\title{
Impact of Osmotic Distillation on the Sensory Properties and Quality of Low Alcohol Beer
}

\author{
Liguori Loredana $\left(\mathbb{D},{ }^{1}\right.$ De Francesco Giovanni, ${ }^{2}$ Albanese Donatella $\left(\mathbb{D},{ }^{1}\right.$ Mincione Antonio, ${ }^{3}$ \\ Perretti Giuseppe, ${ }^{2}$ Di Matteo Marisa, ${ }^{1}$ and Russo Paola ${ }^{4}$ \\ ${ }^{1}$ Department of Industrial Engineering, University of Salerno, Via Giovanni Paolo II 132, 84084 Fisciano, Italy \\ ${ }^{2}$ Department of Economic and Food Science, University of Perugia, Via San Costanzo, 06126 Perugia, Italy \\ ${ }^{3}$ Department of Agriculture, Mediterranean University of Reggio Calabria, C.da Melissari, Reggio Calabria, Italy \\ ${ }^{4}$ Department of Chemical Engineering Materials Environment, Sapienza University of Rome, Via Eudossiana 18, 00184 Roma, Italy
}

Correspondence should be addressed to Liguori Loredana; lliguori@unisa.it

Received 27 October 2017; Accepted 19 December 2017; Published 21 January 2018

Academic Editor: Jesús Lozano

Copyright (C) 2018 Liguori Loredana et al. This is an open access article distributed under the Creative Commons Attribution License, which permits unrestricted use, distribution, and reproduction in any medium, provided the original work is properly cited.

\begin{abstract}
The production of low alcohol beer (LAB) with a full and well-balanced flavour is still now a complex challenge because of the different flavour profile they have compared to regular beers. In this study, a brown ale beer was used to obtain a low alcohol beer by osmotic distillation in a small pilot plant. Beer-diluted carbonated solutions were used as strippers and were taken under flux of $\mathrm{CO}_{2}$ in order to contrast loss of volatiles from beer during the process. A forced carbonation was applied on LAB to avoid the foam collapse. Furthermore, hop extract and pectin solution were added to LAB to improve the overall taste and body. Results highlighted an improvement into retention of volatiles probably due to the use of carbonated solutions such as strippers. The forced carbonation and the addition of pectins ensured both a higher concentration of dissolved $\mathrm{CO}_{2}$ and a higher stability of foam in LAB. The antioxidant activity of beer remained unchanged. The sensory analysis highlighted differences among low alcohol beer and original one. The addition of hop extract and pectin solution to LAB better maintained hop and fruity-citrus notes during tasting, compared with the original beer.
\end{abstract}

\section{Introduction}

Beer is one of the most popular drinks and it is part of the daily diet or fun and celebration situations of millions of people.

In last years, specialty beers (i.e., low-calorie, low alcohol $(<1.2 \% \mathrm{vol})$, alcohol-free $(<0.5 \% \mathrm{vol})$, gluten-free, and functional beers) have become increasingly appealing to consumers because of health reasons [1].

In particular, low alcohol (LAB) and alcohol-free beer can be a good alternative to standard soft drinks in situations when drinking alcoholic beverages is restricted for working, driving regulations, or for health (i.e., weight issues) and religious reasons.

From marketers' perspective, LAB may also represent an opportunity to overcome the limitations set by local authorities regarding the sale of alcoholic beverages, as well as the excise duty, and to expand the market towards countries where the sale of alcoholic beverages is restricted or forbidden for religious reasons [2].

From consumers' point of view, LAB could be considered a potentially attractive rehydration drink for maintaining electrolyte homeostasis during exercise due to the considerable sodium content $(80-100 \mathrm{mg} / \mathrm{L})$, with higher preference among athletes and relatively reduced economic cost [3].

Nevertheless, the consumption of low alcohol beer suggests neutral and negative emotional responses. People tend to associate $\mathrm{LAB}$ as a substitute of regular beer, remaining disappointed in terms of taste, flavour and expectation, which are not comparable to the regular ones. On the other hand, LAB should be treated as a beverage in its own right, avoiding direct comparison with regular beer. Such awareness should be raised through proper advertising. 
TABLE 1: Mashing schedule performed for wort process.

\begin{tabular}{lccccc}
\hline Malt type & $\begin{array}{c}\text { Two-roll } \\
\text { milling }\end{array}$ & $\begin{array}{c}\text { Water/grist } \\
\text { ratio }\end{array}$ & Mashing steps & $\begin{array}{c}\text { Hops pellet } \\
\text { /IBU }\end{array}$ & Boiling/min \\
\hline $\begin{array}{l}\text { Monaco I } \\
\begin{array}{l}\text { Special B } \\
\text { Abbey }\end{array}\end{array}$ & $1 \mathrm{~mm}$ & $3: 1$ & $\begin{array}{c}5^{\prime} \text { at } 56^{\circ} \mathrm{C}, \\
40^{\prime} \text { at } 71^{\circ} \mathrm{C}, \\
5^{\prime} \text { at } 78^{\circ} \mathrm{C}\end{array}$ & $\begin{array}{c}\text { H. Magnum } / 18 \\
\text { IBU }\end{array}$ & 60 \\
\hline
\end{tabular}

LABs can be produced by different methods, which can be classified in two groups: restricted ethanol formation or ethanol removal methods [4]. In the former, the removal of yeasts, or the suppression of yeasts metabolism, allows to limit alcohol formation in the early stage of the brewing process. In the latter, post-fermentation methods consist of removing alcohol from regular beer through thermal or membrane process.

Quality characteristics of LAB depend on the selected method which may affect the beer quality. From one side, it is hardly feasible to achieve low alcohol levels with adequate conversion of wort to beer using biological methods, hence a worty flavour is predominant in LAB. On the other side, thermal degradation causes loss of volatiles and hence body, aroma, and $\mathrm{CO}_{2}$ content change. On the contrary, membrane processes lead to LAB with fuller and better taste, even if losses of sensorial harmony and body were also registered [4].

Among membrane processes, the osmotic distillation is a gentle membrane technique for partial or total reduction of alcohol in beverages as reported in literature [5-10]. The transport of small molecules (ethanol) is allowed from the higher concentration side (beer) to the lower one (stripper). The optimization of process parameters is a priority in order to minimize volatile compounds reduction in beverages during the process.

Firstly, Varavuth et al. [11] reported that water is a more promising stripper of ethanol compared with glycerol and $\mathrm{CaCl}_{2}$ for wine dealcoholization, because it provides higher ethanol flux and lower countertransport of water due to the low water activity differences. Therefore, in preliminary studies on beer dealcoholization [12-14], we used first water as stripper and then alcoholic solutions (permeates) obtained by previous dealcoholization process. This latter resulted as a valid alternative in order to reduce water consumption and minimize the environmental impact of the process, although a significant loss of volatile compounds was observed. In a further study we optimized the stripper solutions composition made by dilution of original beer with water and subsequent carbonation up to saturation at ambient temperature [5]. In fact, in these conditions, lower loss of volatile compounds was detected in low alcohol beer.

Hereinbefore, the production of LAB with a full and wellbalanced flavour is still now a complex challenge. In this study, a brown ale beer was used to obtain a low alcohol beer. An ale beer was chosen because ale beers, fermented at high temperatures, are more fruity, sweeter, and of fuller body than lagers [15].

The ale LAB was produced through osmotic distillation in a small pilot plant, using beer-diluted sparkling solutions as strippers keeping $\mathrm{CO}_{2}$ in flux during all process and, applying forced carbonation on the final product, in order to avoid the foam collapse usually associated with LABs, when these are obtained through physical methods.

The quality and sensory properties of the ale LAB were then investigated. Furthermore, the addition of raw material extracts (i.e., hop) and pectin solution to LAB was performed in order to improve the overall taste and body of the produced low alcohol beer.

\section{Materials and Methods}

2.1. Ale Beer Production. The wort used for the ale beer was produced in $30 \mathrm{~L}$ in the pilot scale brewery at CERB (Perugia, Italy). The grains used were Munich I (70\%) and Abbey (10\%) from Weyermann (Bamberg, Germany) and Special B (20\%) from Castle Malting (Beloeil, Belgium). Hallertau Saphir hop (4.8\% $\alpha$-acids) from Barth-Haas (Nuremberg, Germany) was used to add bitterness. The wort was produced by a multiplestep infusion mashing (Table 1). $5 \mathrm{~kg}$ of malt was crushed and mixed with $15 \mathrm{~L}$ of heated water into the mash tun for the mashing process. $5 \mathrm{~mL}$ of lactic acid solution (80\%) was used to regulate the $\mathrm{pH}$ of the mash to about 5.5. After mashing, the mash extract was drown off from lauter tun and, at the same time, additional $20 \mathrm{~L}$ of water with a $\mathrm{pH} 5.2$ was sprinkled over for the sparging process. Boiling time was for $60 \mathrm{~min}$, followed by a clarification into the whirlpool vessel. $25 \mathrm{~L}$ of hopped and clarified wort was started by adding $11.5 \mathrm{~g}$ of dry yeast Safale S-04 (Fermentis, Marcq en Baroeul Cedex, France). The fermentation was carried out at $\sim 22^{\circ} \mathrm{C}$ for 7 days, and then temperature was gradually lowered to $0-2^{\circ} \mathrm{C}$ over the following 4 days. After racking, the rough beer was stored in a maturation vessel under a slight $\mathrm{CO}_{2}$ overpressure at $4.0 \pm 0.5^{\circ} \mathrm{C}$ for about 15 days and then bottled.

2.2. Small Pilot Plant for Dealcoholization. A membrane module with hollow fibers $(1.7 \times 5.5$ MiniModule, Liqui-Cel, Wuppertal, Germany) was used for beer dealcoholization. Its characteristics were reported in Table 2. The beer flowed in the membrane shell side, countercurrently to the stripper (i.e., carbonated beer-diluted solution) which circulated in the tube side.

The process temperature was set at $10^{\circ} \mathrm{C}$. Feed pressure was measured by a manometer; the flow rates of beer $(0.75 \mathrm{~L})$ and of stripper $(1.5 \mathrm{~L})$ were 0.7 and $1.4 \mathrm{~L} / \mathrm{min}$, respectively. The scheme of the small pilot plant was previously reported [5].

The dealcoholization of the original beer $(\mathrm{OB})$ was performed in 2 cycles, during which both streams were recirculated through the membrane. In particular, the strippers for the 1st and 2nd cycle were obtained by diluting the original beer up to 0.8 and $0.5 \%$ vol of alcohol, respectively [5]. Before 


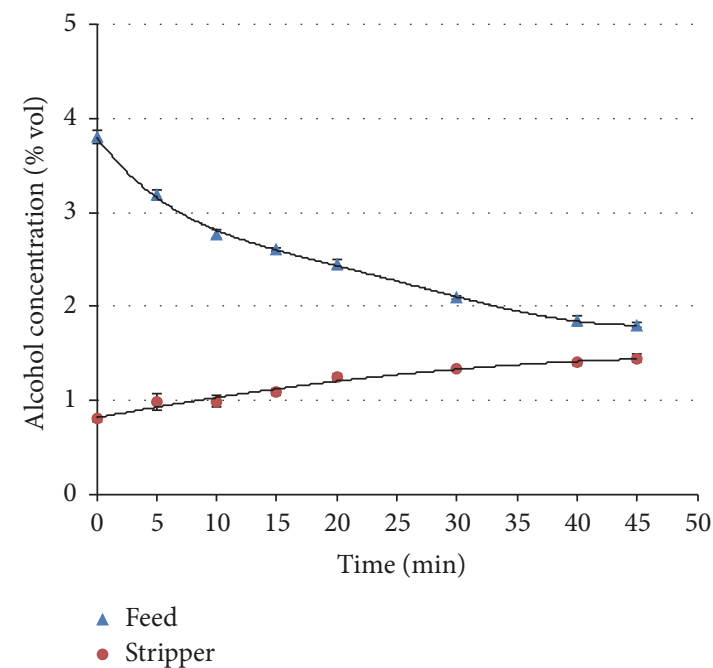

(a)

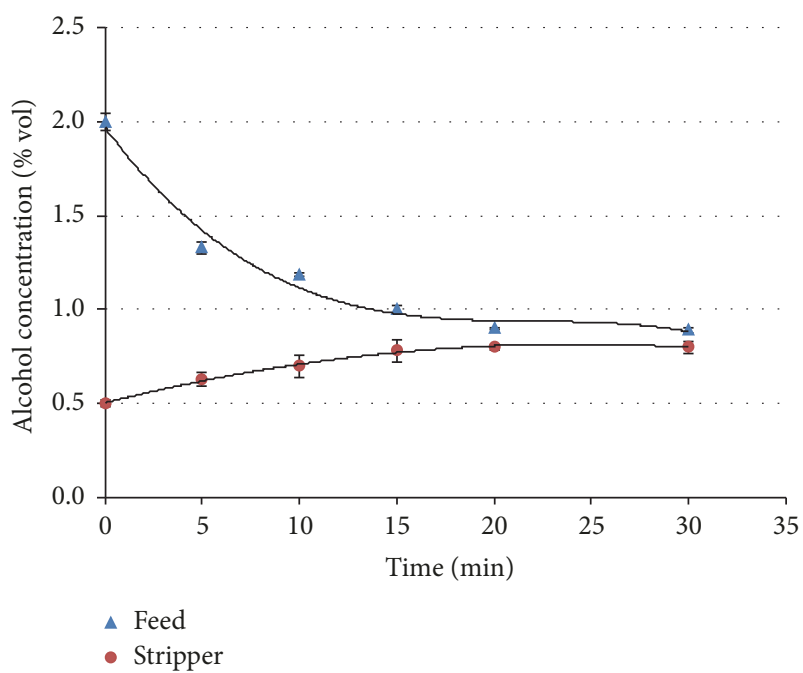

(b)

Figure 1: Dealcoholization kinetic of hydroalcoholic solutions: (a) feed and stripper at 3.8 and $0.8 \%$ vol, respectively; (b) feed and stripper at 2 and $0.5 \%$ vol, respectively.

TAble 2: Membrane module $(1.7 \times 5.5$ MiniModule, Liqui-Cel $)$ specifications.

\begin{tabular}{lc}
\hline Parameters & \\
\hline Membrane & $\times 50$ \\
Membrane material & Polypropylene \\
Membrane surface area $\left(\mathrm{m}^{2}\right)$ & 0.5 \\
Membrane lenght $(\mathrm{cm})$ & 14 \\
Membrane porosity $(\%)$ & 40 \\
Membrane pore size $(\mu \mathrm{m})$ & 0.03 \\
Number of fibers & 6600 \\
Fiber length $(\mathrm{cm})$ & 14 \\
Fiber inner diameter $(\mu \mathrm{m})$ & 220 \\
Fiber outer diameter $(\mu \mathrm{m})$ & 300 \\
\hline
\end{tabular}

each dealcoholization cycle, the strippers were carbonated up to $2.2 \mathrm{~g} / \mathrm{L} \mathrm{CO}$, and during the cycles $\mathrm{CO}_{2}$ flow was set at $0.06 \mathrm{~L} / \mathrm{min}$ in the stripper solution. The cycle time was equal to 40 and $30 \mathrm{~min}$ for 1 st and 2 nd cycles, respectively. The dealcoholization time was determined on the basis of kinetic results performed on model solutions (Figures 1(a)-1(b)).

A total number of 14 batches of the dealcoholized beer $(1.1 \%$ vol) were produced and mixed $(10 \mathrm{~L})$. A batch $(5 \mathrm{~L})$ of dealcoholized beer was then carbonated at 2 bar (LAB). Hop (Humulus lupulus, cascade variety, 6.8\% $\alpha$-acids) extract and pectins solutions at a concentration of $2 \mathrm{~mL}$ each in $100 \mathrm{~mL}$ were added to another batch $(5 \mathrm{~L})$ of dealcoholized beer and then carbonated at 2 bar $(\mathrm{LAB}+)$.

2.3. Chemical Analyses. The main quality attributes (original, real, and apparent extracts; alcohol content, $\mathrm{pH}$, colour, turbidity, bitterness, total nitrogen, $\mathrm{O}_{2}$ and $\mathrm{CO}_{2}$ content and foam stability) of original beer and low alcohol beers were investigated. All the analyses were performed according to Analytica-EBC methods [16].

The total phenol content was determined with the FolinCiocalteu (FC) assay [17]. Gallic acid as reference compound was used for calibration curve and results were expressed as gallic acid equivalent (GAE) mg/L beer.

The antioxidant activity (AA) was evaluated by the DPPH scavenging method [18] using a spectrophotometer (Perkin Elmer, Lambda Bio 40). The percentage inhibition of remaining DPPH was calculated according to Liguori et al. [5]. A calibration curve of Trolox standard was used and results were expressed as Trolox equivalent (TE) $\mu \mathrm{mol} / \mathrm{L}$ beer.

The volatile compounds concentration was determined by Gas Chromatograph (Agilent Technologies 6850) equipped with Mass Spectrometer (Agilent Technologies 5975C) and with a Maestro Autosampler Gerstel Multi-Purpose Sampler (SPME GC/MS). The method used was based on that developed by Vesely et al. [19] and subsequently slightly modified [10]. The analyses were carried out in duplicate.

2.4. Sensory Analysis. The sensory analysis was carried out by a trained panel (composed by 12 judges aged between 25 and 45 years) through description analysis according to Analytica-EBC method 13.10 [16]. The panellists were asked to describe, in the three beers under evaluations, 14 flavour attributes for the taste (fruity/esters, alcoholic/solvent, fruitycitrus, cereal, malty, caramel, burnt, bitter, sweet, sour, astringent, body, and linger) and 9 flavour attributes for the aroma (fruity/esters, alcoholic/solvent, fruity-citrus, cereal, malty, caramel, burnt, and sweet). For each attribute, a score was assigned ranging from 0 to 9 . A score of 0 meant that the attribute was absent whereas a score of 9 indicated that the attribute was extremely strong. Both replicates of each beer were blind-tested and the mean of the results was reported in spider plots. Sensory descriptive data were also submitted to 
TABLE 3: Quality parameters of original beer (OB), low alcohol beer (LAB), and low alcohol beer added with hop extract and pectin solution $(\mathrm{LAB}+)$.

\begin{tabular}{|c|c|c|c|}
\hline Parameters & $\mathrm{OB}$ & LAB & $\mathrm{LAB}+$ \\
\hline Ethanol (\% vol) & $3.8 \pm 0.1^{\mathrm{a}}$ & $1.1 \pm 0.1^{\mathrm{b}}$ & $1.1 \pm 0.1^{\mathrm{b}}$ \\
\hline Original extract (wt\%) & $12.2 \pm 0.1^{\mathrm{a}}$ & $8.2 \pm 0.1^{\mathrm{b}}$ & $7.9 \pm 0.2^{\mathrm{c}}$ \\
\hline Apparent extract (wt\%) & $5.31 \pm 0.0^{\mathrm{a}}$ & $4.03 \pm 0.0^{\mathrm{b}}$ & $4.14 \pm 0.0^{\mathrm{c}}$ \\
\hline Real extract (wt\%) & $6.49 \pm 0.08^{\mathrm{a}}$ & $4.72 \pm 0.01^{\mathrm{b}}$ & $4.75 \pm 0.01^{\mathrm{b}}$ \\
\hline $\mathrm{pH}$ & $4.33 \pm 0.01^{\mathrm{a}}$ & $4.19 \pm 0.10^{\mathrm{a}}$ & $4.18 \pm 0.10^{\mathrm{a}}$ \\
\hline Colour (EBC) & $94.7 \pm 2.5^{\mathrm{a}}$ & $84.0 \pm 3.0^{\mathrm{b}}$ & $83.4 \pm 4.7^{\mathrm{b}}$ \\
\hline Total phenols (mg GAE/L) & $908.0 \pm 100.2^{\mathrm{a}}$ & $1015.4 \pm 73.8^{\mathrm{a}}$ & $1053.3 \pm 81.3^{\mathrm{a}}$ \\
\hline DPPH-Trolox equivalent antioxidant capacity $(\mu \mathrm{M} / \mathrm{L})$ & $1321.8 \pm 89.3^{\mathrm{a}}$ & $1135.6 \pm 378.5^{\mathrm{a}}$ & $1264.3 \pm 129.3^{\mathrm{a}}$ \\
\hline Bitterness (BU) & $20.0 \pm 1.0^{\mathrm{a}}$ & $21.0 \pm 1.0^{\mathrm{a}}$ & $23.0 \pm 1.0^{\mathrm{b}}$ \\
\hline Total Nitrogen (mg/L) & $567.0 \pm 27.0^{\mathrm{a}}$ & $561.0 \pm 30.0^{\mathrm{a}}$ & $569.0 \pm 23.0^{\mathrm{a}}$ \\
\hline Foam stability Nibem $30 \mathrm{~mm}$ (s) & $156.0 \pm 5.0^{\mathrm{a}}$ & $185.0 \pm 4.0^{\mathrm{b}}$ & $236.0 \pm 1.0^{c}$ \\
\hline Turbidity (EBC) & $7.0 \pm 0.0^{\mathrm{a}}$ & $3.2 \pm 0.1^{\mathrm{b}}$ & $2.5 \pm 0.2^{c}$ \\
\hline $\mathrm{O}_{2}(\mathrm{mg} / \mathrm{L})$ & $47.0 \pm 5.0^{\mathrm{a}}$ & $105.0 \pm 25.0^{\mathrm{b}}$ & $133.0 \pm 28.0^{\mathrm{b}}$ \\
\hline $\mathrm{CO}_{2}(\mathrm{~g} / \mathrm{L})$ & $6.0 \pm 0.0^{\mathrm{a}}$ & $4.8 \pm 0.93^{\mathrm{b}}$ & $4.5 \pm 0.1^{\mathrm{b}}$ \\
\hline
\end{tabular}

Data represent the mean of 3 replicates \pm SD. Different letters correspond to statistically significant differences among original beer (OB) and low alcohol beer (LAB) and low alcohol beer added with hop extract and pectin solution (LAB+) according to one-way ANOVA followed by Student's $t$-test $(P<0.05)$.

Principal Component Analysis (Unscrambler v10.4, CAMO Software, Norway).

2.5. Statistical Analysis. Brewing trials, dealcoholization tests, and analytical measurements were carried out in triplicate and mean values and standard deviation values were subjected to monofactorial variance analysis (ANOVA). The significance of differences $(P<0.05)$ among samples was determined by Student's $t$-test. Statistical analysis was performed using Analysis Lab software.

\section{Results and Discussion}

3.1. Dealcoholization of Beer. The target was the production of beer with an alcohol content less than $1.2 \%$ vol. To achieve this, the required cycle numbers and their duration were evaluated by preliminary dealcoholization tests using a hydroalcoholic solution (about 3.8\% vol) as feed to mimic the original ale beer). Figures 1(a) and 1(b) show the temporal profiles of alcohol concentration in feed and stripper. Based on these results, the dealcoholization process of the original beer is performed in two cycles using as stripper beer-diluted solutions at 0.8 and $0.5 \%$ vol and a duration of 40 and $30 \mathrm{~min}$ for the 1st and 2 nd cycle, respectively.

Such process parameters have allowed reaching an alcohol concentration of $1.1 \%$ vol, lower than the maximum level for $\mathrm{LAB}$ which is $1.2 \% \mathrm{vol}$ in most of European countries (Table 3).

3.2. Quality Parameters of Original and Low Alcohol Beers. The comparison of the main quality parameters measured in the three beer samples $(\mathrm{OB}, \mathrm{LAB}$, and $\mathrm{LAB}+)$ is reported in Table 3. A significant decrease $(P<0.05)$ in real, original, and apparent extract parameters is observed in low alcohol beers, according to previous studies $[10,20]$ in which craft beers produced by semi-industrial scale plant or commercially available were analysed, respectively.
The $\mathrm{pH}$ of beer is an important parameter for shelf life and resistance to microbial contaminations [21]. The $\mathrm{pH}$ value of all samples is very similar (Table 3 ) and in the range of 4.13-4.97 as reported in literature $[4,22]$.

Colour is one of the main physical properties assessed by a beer drinker beside clarity, viscosity, and foam. Obviously, the colour depends on the process parameters used for the roasting of the barley, which induces Maillard browning reactions and in some cases caramelization and pyrolysis reactions [23]. OB samples show a colour of $94.7 \mathrm{EBC}$, according to the range of dark beer (45-95 EBC units) that significantly decreases $(P<0.05)$ in LAB and LAB+ beers. No differences in colour have been observed between the two LAB samples prior and after the addition of hop extract and pectins (Table 3). Similar findings were reported for alcoholfree beers obtained by physical methods [4].

Polyphenols are the most important compounds among the antioxidant components of the beer [24]. Endogenous phenolic compounds, especially flavonoids and hydroxycinnamic acids, which are present in barley, naturally inhibit oxidative deterioration, improve flavour stability of beer, and could be protected and promoted by the malting process [25]. Phenolic compounds have several functional properties in the beer: they influence its colloidal stability interacting with binding sites of haze-active proteins and moderate sensory astringency and influence aging and colour [26].

The amount of total phenols in beer varies significantly depending on raw materials and beer style. The ale beer used in this study is richer in phenol compounds (about $900 \mathrm{mg}$ GAE/L) than the ale beers (about 563-875 mg GAE/L) studied by Piazzon et al. [27], because of the different types of malts and their amount. According to our previous study [5], no significant difference $(P<0.05)$ in phenol content is found before and after dealcoholization process. Both low alcohol beers show a content of phenols higher than the dealcoholized beers on the market (366 mg GAE/L) [27]. 
The original beer shows high value of antioxidant activity (AA), confirming the superior antioxidant capacity of ale beer with respect to other styles [28]. No significant $(P<$ 0.05 ) differences in AA are detected among the beer samples confirming that the process has not negatively influenced the healthy properties of this type of beverage.

Turbidity gives a first visual impression of the quality of the beer to the consumer and, from the analytical measurements (Table 3), original beer appears hazy. The values of turbidity significantly decrease $(P<0.05)$ after the dealcoholization process because of the filtering effect of the membrane. Similar results were found in previous studies about low alcohol and light beers where a reduced tendency to form cold and permanent haze was found $[10,20]$.

The dealcoholization process causes also $\mathrm{CO}_{2}$ losses, which influence the foam formation. In a previous study [5], we highlighted a huge reduction of dissolved $\mathrm{CO}_{2}$ and foam production. For this reason, in this study, a forced carbonation was performed for both $\mathrm{LAB}$ and $\mathrm{LAB}+$ samples.

The results (Table 3 ) show for both $\mathrm{LAB}$ and $\mathrm{LAB}+\mathrm{a}$ higher stability of foam head than for the $\mathrm{OB}$ sample. The higher value of foam stability detected in LAB+ samples is probably due to the addition of pectins which add palatefullness and a higher foam stability to the beer [29].

Finally, $\mathrm{O}_{2}$ content is increased in LAB samples probably due to oxygenation during the dealcoholization process.

3.3. Volatiles Composition and Sensory Analysis. Many chemical compounds play a key role in the development of the sensory profile of beer. Among them volatile compounds, coming from raw materials or produced during brewing, contribute greatly to the flavour or are important merely in building up the background flavour of the beer [30].

The volatile composition of $\mathrm{OB}, \mathrm{LAB}$, and $\mathrm{LAB}+$ is shown in Table 4. Four classes of compounds are identified: higher alcohols, esters, aldehydes, and ketones.

Higher alcohols are formed during yeast metabolism, as byproducts of amino acid synthesis from pyruvate through the anabolic pathway or they could be produced through amino acid catabolism. These compounds may positively contribute to the flavour of the beer if their amount is lower than $300 \mathrm{mg} / \mathrm{L}$ ( $118.82 \mathrm{mg} / \mathrm{L}$ for OB beer). The higher alcohols identified in beer samples are as follows: amyl alcohols, isobutanol, propanol, 2-phenylethanol, and furfuryl alcohol.

Isoamyl alcohol is the most abundant among the aliphatic alcohols and cause "fruity" notes. It influences beer drinkability: increased concentrations of isoamyl alcohol cause the beer to become heavier. The other aliphatic alcohols are responsible for "solvent" aroma of beer and produce a warm mouthfeel.

Esters give a pleasant, full-bodied character to beer aroma, but in high concentration they give an overly fruity quality, which is considered undesirable by most consumers [31].

A total of five ester compounds is identified in original beer, all typical for the beer volatile fraction. These compounds are found in an amount lower than their threshold concentration (Table 4). This condition represents a positive aspect for the beer drinkability because when the concentration of these esters exceeds their threshold, it causes an undesirable flavour to the beer. It is noteworthy that the presence of different esters can have a synergistic effect, and thus they can also affect beer flavour even if they are present in concentrations well below their flavour threshold.

The other classes of compounds identified in the volatile fraction are aldehydes and ketones.

Fresh beer generally contains rather low concentrations of these aldehydes, below their respective flavour thresholds [32]. Acetaldehyde is the most abundant in all beer samples (Table 4), as reported elsewhere $[5,10,33]$. This aldehyde is difficult to categorize under just one specific formation mechanism: acetaldehyde can be produced as a byproduct of glycolysis during fermentation or can be formed by Strecker degradation of alanine [32].

The other aldehydes detected in beer come from aging process. In particular, 2-methylbutanal, 3-methylbutanal, methional, and phenylacetaldehyde arise from Strecker degradation products which occur by a transamination between $\alpha$-dicarbonyl products and amino acids. They might play a central role in flavour modification during beer aging. Hexanal is related to the autoxidation of linoleic acid while furfuraldehyde is the most important product of the Maillard reaction in beer.

According to several authors, furfuraldehyde does not exceed its flavour threshold value, and it is therefore said that it does not significantly affect beer flavour. This is contradicted by De Clippeleer et al. [34], who reported that the addition of furfuraldehyde to fresh pale lager beer resulted in a sharper, harsher, more linger, bitter and astringent beer.

The other compounds detected in beer are vicinal diketones, also produced as byproducts of the synthesis pathway of some amino acids during fermentation and diacetyl, that is, more flavour-active than the other, mainly responsible for the buttery flavour in beer [33].

The dealcoholization process causes losses of all volatile compounds that are reduced of about $55 \%$ respect to the original beer. The highest decrease is observed for esters followed by higher alcohols and aldehydes compounds. About ketones, an increase is detected in both dealcoholized beers probably due to oxygenation phenomenon occurring prior to carbonation step.

A higher retention of volatiles is obtained in this study with respect to our previous ones [13,14]. This improvement is probably due to the use of carbonated solutions as strippers which obstacle the mass transfer of volatiles through the membrane.

As regards the low alcohol beer modified with hop and pectins, no differences are found with respect to LAB (the low alcohol beer without supplements) except for the increase in all detected aldehydes. Our results may be probably due to the use of a long-standing hop, which has released aldehydes in beer samples as oxidation byproducts.

Previous studies, in fact, highlighted the formation of staling aldehydes in aged hop due to oxidative degradation of lipid and iso- $\alpha$-acids' alkanoyls $[35,36]$.

The physical and chemical properties of the main volatiles detected in the OB are also reported in Table 4. Among them, the flavour threshold may provide information on the 


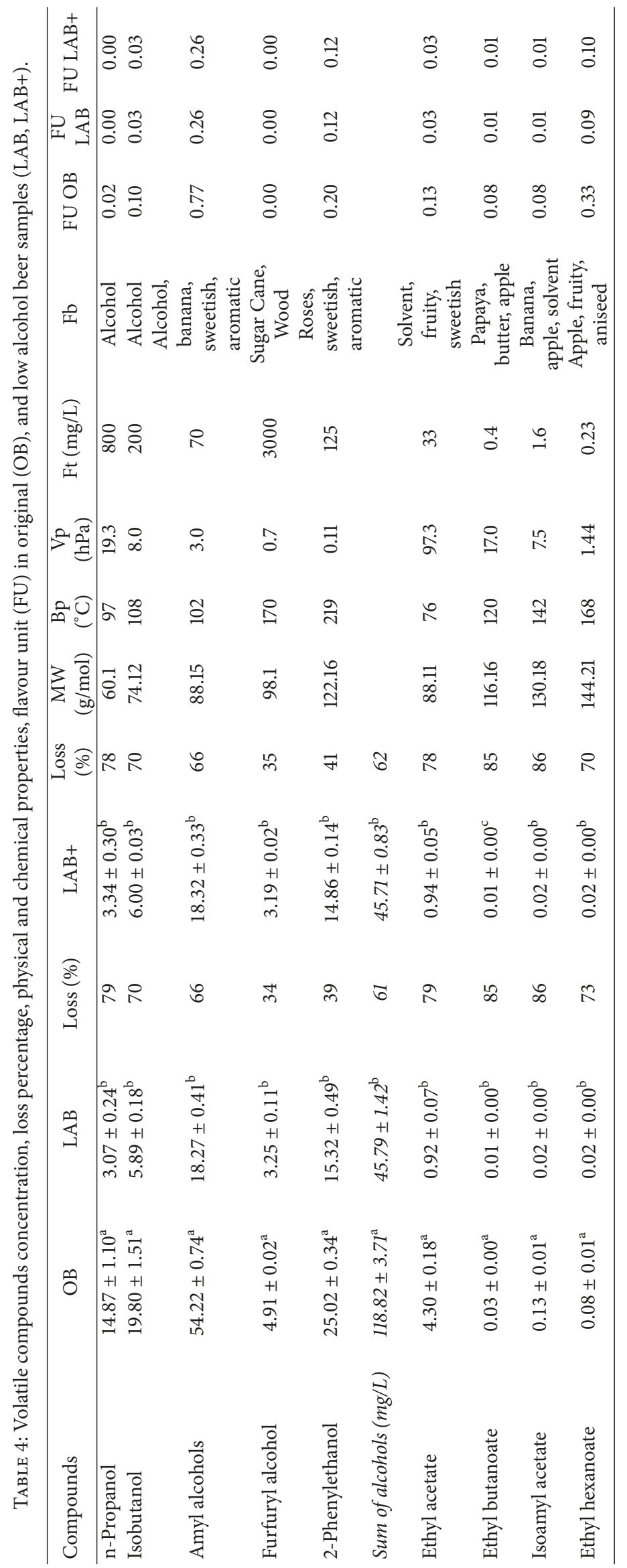




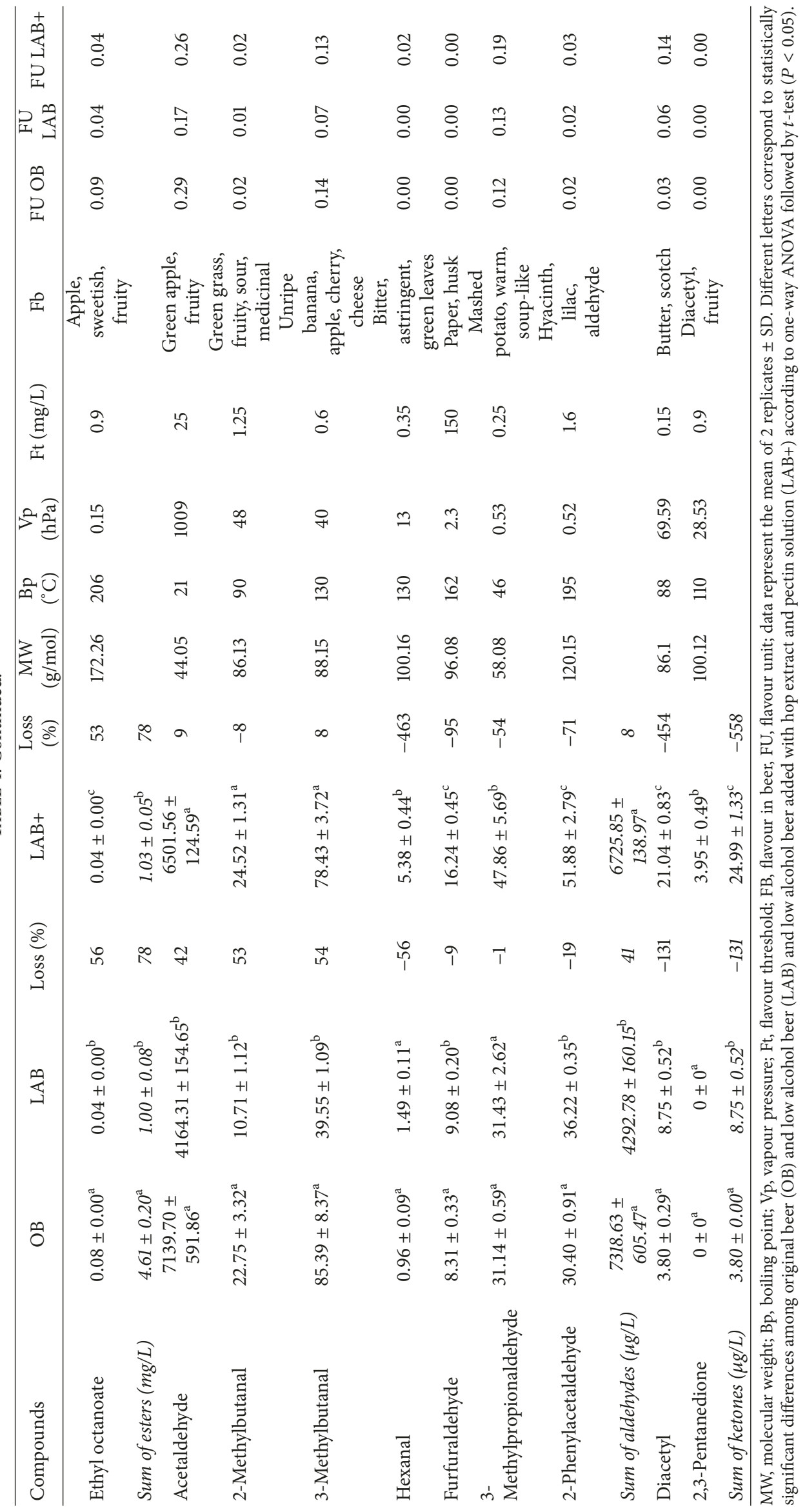




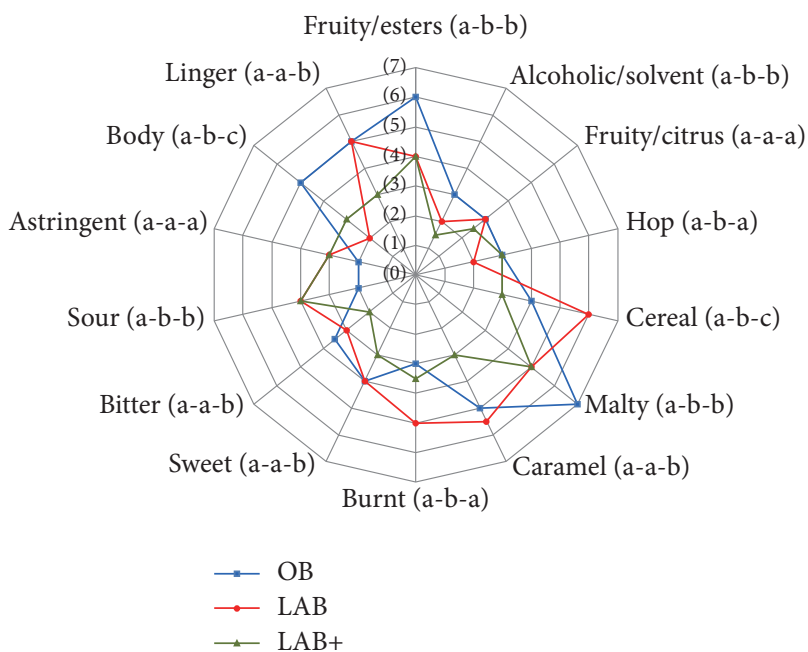

(a)

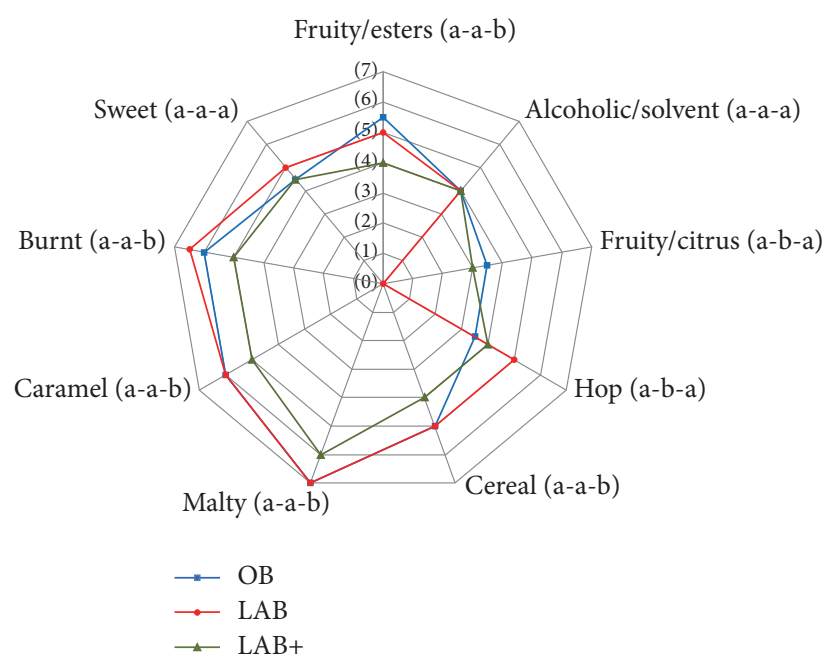

(b)

FIGURE 2: Sensory profile of OB (original beer), LAB (low alcohol beer), and LAB+ (low alcohol beer with supplements): (a) taste and (b) aroma. The letters near the descriptors indicate a statistically significant difference $(P<0.05)$, in the order OB-LAB-LAB+.

impact of a given compound on taste, aroma, and flavour, when compared with the measured concentration of that compound. Therefore, in order to assess the contribution of a specific compound to the overall beer flavour, the "flavour unit" (FU) is introduced. FU is the ratio of the concentration of a flavour-active compound and its threshold value: a 0.5 $\mathrm{FU}$ increase or decrease is perceived by the taster, but the cause may not be identified, whereas it can be identified in the case of a 1 FU change [37]. However, it has to be underlined that the flavour of beer is not be considered as the sum of the individual intensity of each compound because of synergy and/or suppression phenomena that may arise [32].

From Table 4, all volatiles compounds are detected in such concentration that their $\mathrm{FU}$ is lower than 1 in the original ale beer. The higher FU $(0.77,0.33$, and 0.29$)$ in $\mathrm{OB}$ is associated with isoamyl alcohol, ethyl hexanoate, and acetaldehyde, respectively. These results highlight that the brewed beer had not an intense flavour and many volatiles contributed weakly to the overall flavour of original beer. As expected, the $\mathrm{LAB}$ shows a lower $\mathrm{FU}$ for all the compounds while the low alcohol beer with supplements $(\mathrm{LAB}+$ ) shows a FU of aldehydes like the original beer.

The sensory profiles of beer samples $(\mathrm{OB}, \mathrm{LAB}$, and $\mathrm{LAB}+$ ) on taste and aroma are reported in Figures 2(a)-2(b).

The original beer mainly presents fruity ester-like and malty notes; a good body and linger. Similarly, the main aroma notes are malty, caramel, burnt, and fruity/esters. The malty note is a characteristic flavour of malt that may be found especially in dark beers and also fruity ester-like notes is typical of ale beers (Figures 2(a)-2(b)).

The body, as well as the alcoholic/solvent descriptor, is decreased after the removal of ethanol in both low alcohol beers (Figure 2(a)), in which the sour taste is more pronounced than in the original beer. The addition of hop extract and pectin solutions has improved the body of LAB+ sample which is perceived less sweet, with less pronounced cereal, caramel, bitter, and linger notes than LAB sample $(P<0.05)$ (Figure 2(a)).

Regarding the aroma (Figure 2(b)), in LAB+ sample the hop and fruity-citrus notes are perceived as those in the original beer.

Principal Component Analysis (PCA) is performed on sensory panel data related to GC/MS data, taste and aroma descriptors, in order to explain the total variability of the characteristics analysed, using the cross-validation technique.

Including all the volatile compounds, the first principal component (PC1) explains $54 \%$ of the total variation, and $\mathrm{PC} 2$ explains $23 \%$ of the total variation. The PCA shows a good separation of the beer samples which are clearly defined.

The OB sample forms a clear group in the negative quadrant of the $\mathrm{PCl}$ and is associated with the level of higher alcohols and esters (Figures 3(a)-3(b)). The LAB samples are located in the positive PC1 quadrant of PCA plot and are largely associated with aldehydes and ketones, as shown also in the Table 4.

The biplot of PCA based on the taste data of panellists (Figures 4(a) and 4(b)) points to a separation of the beer samples in three groups, confirming the significant differences found by the sensory analysis for the taste attributes.

In particular, OB sample is mostly correlated to body, fruity/esters, fruity/citrus, malty, and alcohol; burnt, astringent, and cereal are better associated with LAB sample. No significant correlations of taste descriptors with $\mathrm{LAB}+$ sample are found.

On the whole, the low alcohol beers ( $\mathrm{LAB}$ and $\mathrm{LAB}+$ ) are negatively correlated with $\mathrm{PCl}$ and so correlated with sour, astringent, burnt, cereal, and caramel descriptors; the $\mathrm{OB}$ is plotted in the positive quadrant of PC1 and PC2 and it is strongly correlated with most of taste descriptors.

On the basis of analysed aroma descriptors (Figures $5(\mathrm{a})-5(\mathrm{~b})), \mathrm{PCl}$ explains $36 \%$ of the variance in the dataset, 


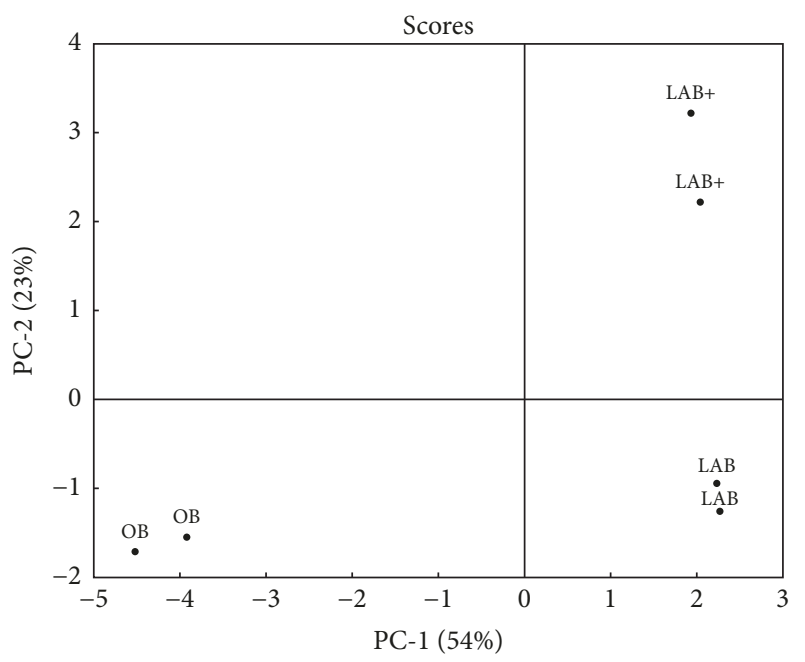

(a)

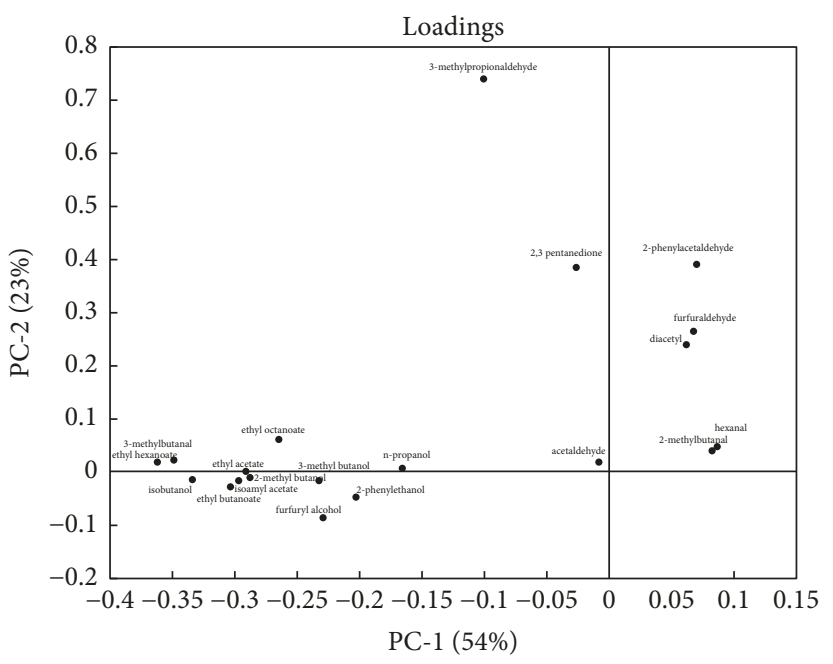

(b)

FIgURE 3: PCA plots of volatile compounds of OB, LAB, and LAB+ samples: (a) score plot and (b) loading plot.

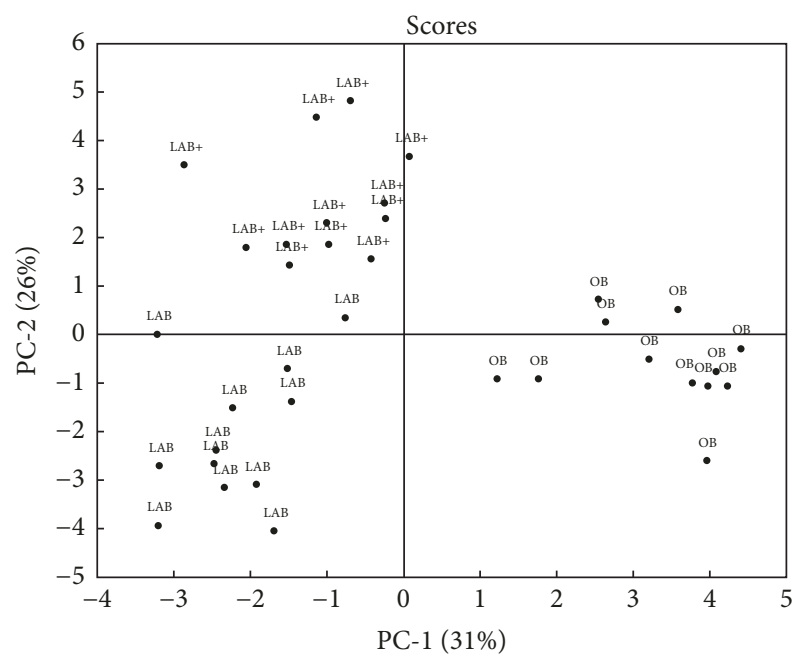

(a)

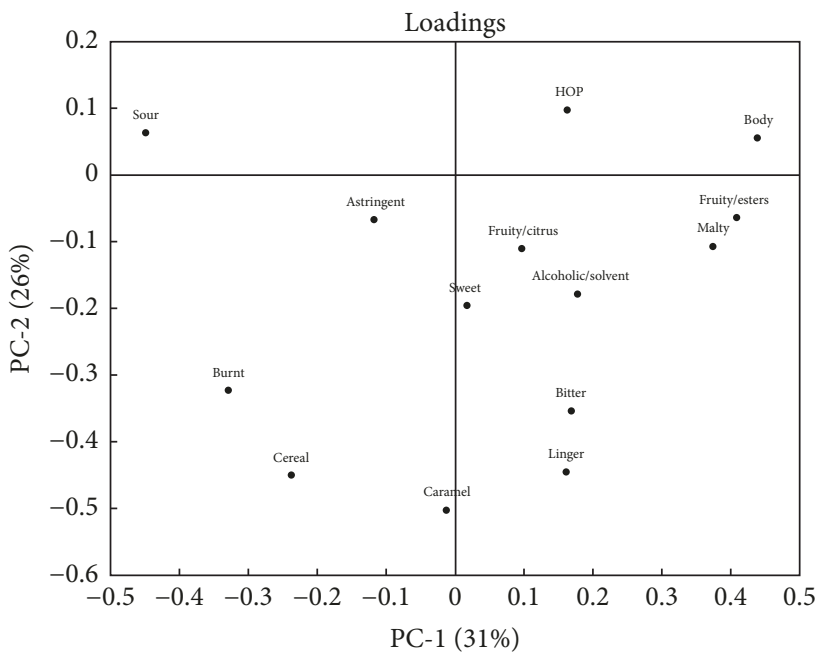

(b)

Figure 4: PCA plots of taste sensory evaluation of OB, LAB, and LAB+ samples: (a) score plot and (b) loading plot.

whereas PC2 explains an additional $16 \%$ of the variance. The beer samples are variously distributed and $\mathrm{LAB}+$ sample is overlapped with $\mathrm{OB}$ in the positive $\mathrm{PCl}$ quadrant, in terms of fruity-esters, fruity-citrus, and alcoholic descriptors. Sweet and fruity-citrus descriptors show an evident correlation with the OB sample, while burnt and hop are more related to the LAB sample.

In this study, the PCA discriminates the beer samples mainly in terms of analytical composition of volatiles and sensory analysis of taste; on the contrary, PCA shows some relationship in terms of aroma, as perceived by panellists between $\mathrm{LAB}+$ and $\mathrm{OB}$ samples.

\section{Conclusions}

Low alcohol ale beer $(1.1 \%$ vol $)$ was produced through osmotic distillation technique in a small pilot plant. The large amount of phenolic compounds in the ale beer, which are of huge interest for the brewing industry for their potential health benefits, was unchanged after dealcoholization. An improvement with respect to the previous studies was achieved. The forced carbonation (LAB) and the addition of pectins $(\mathrm{LAB}+)$ ensured both a higher concentration of dissolved $\mathrm{CO}_{2}$ and a higher stability of foam in LAB. Although a loss of volatiles still occurred, higher retention of higher alcohols was obtained by fluxing $\mathrm{CO}_{2}$ in stripper side during the process.

The original beer mainly presented fruity (ester-like) and malty notes, a good body and linger. Results of the sensory analysis highlighted that some differences among $\mathrm{LAB}$ samples and $\mathrm{OB}$ still remained for body and the main descriptors when the beers were tasted.

Analysis of taste descriptors showed greater correlation with "burnt," "astringent," and "cereal" descriptors for the 


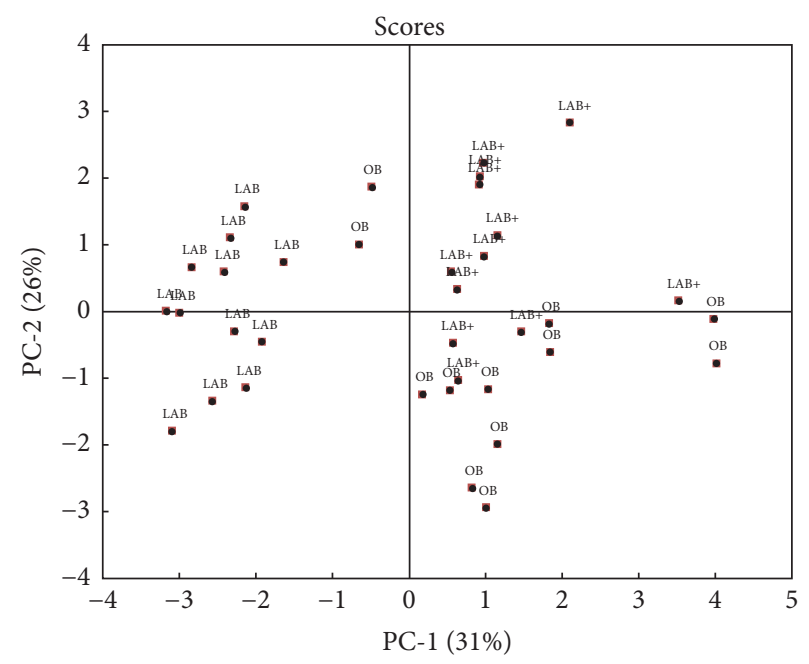

(a)

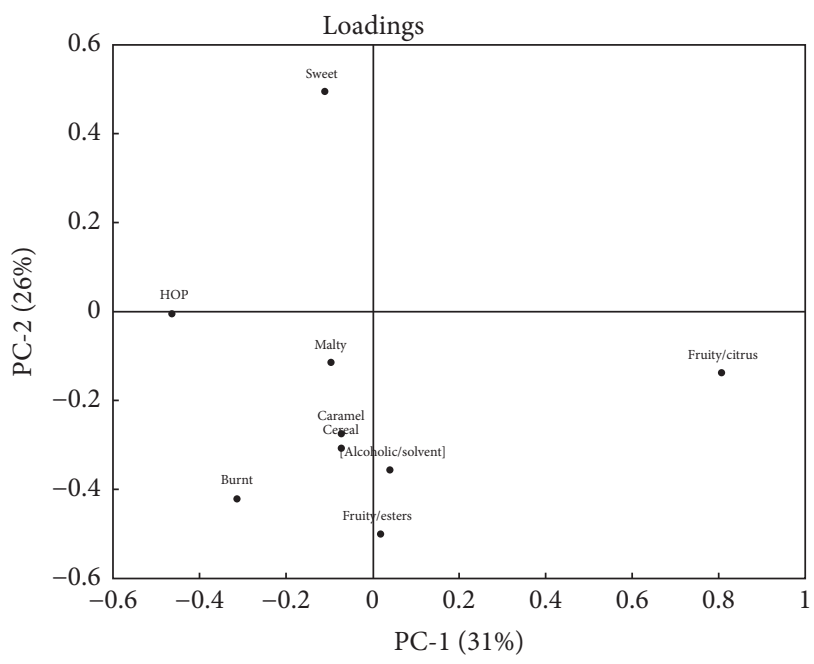

(b)

FIGURE 5: PCA plots of aroma sensory evaluation of OB, LAB, and LAB+ samples: (a) score plot and (b) loading plot.

LAB sample, while "body," "fruity/esters," "fruity/citrus," "malty," and "alcohol" descriptors mostly correlated to the OB sample.

The addition of hop extract and pectin solution allowed maintaining fruity-citrus and hop notes, during the taste, similar to the OB, even if some differences (i.e., cereal and malty) in terms of taste and aroma were still perceived. The PCA analysis results clearly showed a differentiation in volatiles composition among beer samples $(\mathrm{OB}, \mathrm{LAB}$, and $\mathrm{LAB}+)$ although no significant differences in aroma $(P<$ 0.05 ) between $\mathrm{OB}$ and $\mathrm{LAB}+$ samples were perceived.

\section{Conflicts of Interest}

The authors declare that there are no conflicts of interest regarding the publication of this paper.

\section{References}

[1] H. Q. Yeo and S.-Q. Liu, "An overview of selected specialty beers: developments, challenges and prospects," International Journal of Food Science \& Technology, vol. 49, no. 7, pp. 1607-1618, 2014.

[2] S. Porretta and G. Donadini, "A preference study for no alcohol beer in Italy using quantitative concept analysis," Journal of the Institute of Brewing, vol. 114, no. 4, pp. 315-321, 2008.

[3] M. Castro-Sepulveda, N. Johannsen, S. Astudillo et al., "Effects of beer, non-alcoholic beer and water consumption before exercise on fluid and electrolyte homeostasis in athletes," Nutrients, vol. 8, no. 6, article no. 345, 2016.

[4] T. Brányik, D. P. Silva, M. Baszczyňski, R. Lehnert, and J. B. Almeida E Silva, "A review of methods of low alcohol and alcohol-free beer production," Journal of Food Engineering, vol. 108, no. 4, pp. 493-506, 2012.

[5] L. Liguori, G. De Francesco, P. Russo, G. Perretti, D. Albanese, and M. Di Matteo, "Quality attributes of low-alcohol topfermented beers produced by membrane contactor," Food and Bioprocess Technology, vol. 9, no. 1, pp. 191-200, 2016.
[6] L. Liguori, P. Russo, D. Albanese, and M. Di Matteo, "Effect of process parameters on partial dealcoholization of wine by osmotic distillation," Food and Bioprocess Technology, vol. 6, no. 9, pp. 2514-2524, 2013.

[7] L. Liguori, P. Russo, D. Albanese, and M. Di Matteo, "Evolution of quality parameters during red wine dealcoholization by osmotic distillation," Food Chemistry, vol. 140, no. 1-2, pp. 6875, 2013.

[8] L. Liguori, G. Attanasio, D. Albanese, and M. Di Matteo, "Aglianico wine dealcoholization tests," Computer Aided Chemical Engineering, vol. 28, no. C, pp. 325-330, 2010.

[9] R. Ferrarini, G. M. Ciman, F. Camin, S. Bandini, and C. Gostoli, "Variation of oxygen isotopic ratio during wine dealcoholization by membrane contactors: experiments and modelling," Journal of Membrane Science, vol. 498, pp. 385-394, 2016.

[10] G. De Francesco, V. Sileoni, O. Marconi, and G. Perretti, "Pilot plant production of low-alcohol beer by osmotic distillation," Journal of the American Society of Brewing Chemists, vol. 73, no. 1, pp. 41-48, 2015.

[11] S. Varavuth, R. Jiraratananon, and S. Atchariyawut, "Experimental study on dealcoholization of wine by osmotic distillation process," Separation and Purification Technology, vol. 66, no. 2, pp. 313-321, 2009.

[12] P. Russo, L. Liguori, D. Albanese, A. Crescitelli, and M. Di Matteo, "Investigation of osmotic distillation technique for beer dealcoholization," Chemical Engineering Transactions, vol. 32, pp. 1735-1740, 2013.

[13] L. Liguori, G. De Francesco, P. Russo, G. Perretti, D. Albanese, and M. Di Matteo, "Production and characterization of alcoholfree beer by membrane process," Food and Bioproducts Processing, vol. 94, pp. 158-168, 2015.

[14] L. Liguori, G. De Francesco, P. Russo, D. Albanese, G. Perretti, and M. Di Matteo, "Quality improvement of low alcohol craft beer produced by evaporative pertraction," Chemical Engineering Transactions, vol. 43, pp. 13-18, 2015.

[15] A. Pavsler and S. Buiatti, "Non-lager beer," Beer in Health and Disease Prevention, pp. 17-30, 2008.

[16] Analytica-EBC., Verlag Hans Carl, Nurnberg, Germany, 2010. 
[17] V. Singleton and J. A. Rossi, "Colorimetry of total phenolics with phosphomolybdic-phosphotungstic acid reagents," American Journal of Enology and Viticulture, vol. 16, no. 3, pp. 144-158, 1965.

[18] W. Brand-Williams, M. E. Cuvelier, and C. Berset, "Use of a freeradical method to evaluate antioxidant activity," Lebensmittel-Wissenschaft Technologie, vol. 28, pp. 25-30, 1995.

[19] P. Vesely, L. Lusk, G. Basarova, J. Seabrooks, and D. Ryder, "Analysis of Aldehydes in Beer using solid-phase Microextraction with on-fiber derivatization and gas chromatography/mass spectrometry," Journal of Agricultural and Food Chemistry, vol. 51, no. 24, pp. 6941-6944, 2003.

[20] S. Malfliet, K. Goiris, G. Aerts, and L. de Cooman, "Analyticalsensory determination of potential flavour deficiencies of light beers," Journal of the Institute of Brewing, vol. 115, no. 1, pp. 4963, 2009.

[21] S. M. Smedley, "Colour determination of beer using tristimulus values," Journal of the Institute of Brewing, vol. 98, no. 6, pp. 497$504,1992$.

[22] D. Granato, G. F. Branco, J. D. A. F. Faria, and A. G. Cruz, "Characterization of Brazilian lager and brown ale beers based on color, phenolic compounds, and antioxidant activity using chemometrics," Journal of the Science of Food and Agriculture, vol. 91, no. 3, pp. 563-571, 2011.

[23] A. Gresser, "Properties and quality," in Handbook of Brewing, H. Michael Eblinger, Ed., pp. 359-395, Wiley-VCH Verlag GmbH \& Co. KGaA, Weinheim, Germany, 2009.

[24] L. Česlová, M. Holčapek, M. Fidler, J. Drštičková, and M. Lísa, "Characterization of prenylflavonoids and hop bitter acids in various classes of Czech beers and hop extracts using high-performance liquid chromatography-mass spectrometry," Journal of Chromatography A, vol. 1216, no. 43, pp. 7249-7257, 2009.

[25] J. Lu, H. Zhao, J. Chen et al., "Evolution of phenolic compounds and antioxidant activity during malting," Journal of Agricultural and Food Chemistry, vol. 55, no. 26, pp. 10994-11001, 2007.

[26] T. Nakamura, N. Coichev, and H. D. Moya, "Modified CUPRAC spectrophotometric quantification of total polyphenol content in beer samples using $\mathrm{Cu}(\mathrm{II}) /$ neocuproine complexes," Journal of Food Composition and Analysis, vol. 28, no. 2, pp. 126-134, 2012.

[27] A. Piazzon, M. Forte, and M. Nardini, "Characterization of phenolics content and antioxidant activity of different beer types," Journal of Agricultural and Food Chemistry, vol. 58, no. 19, pp. 10677-10683, 2010.

[28] P. A. R. Tafulo, R. B. Queirós, C. M. Delerue-Matos, and M. G. F. Sales, "Control and comparison of the antioxidant capacity of beers," Food Research International, vol. 43, no. 6, pp. 1702-1709, 2010.

[29] D. E. Briggs, C. A. Boulton, P. A. Brookes, and R. Stevens, "The science of mashing," in Brewing science and practice, D. E. Briggs, C. A. Boulton, P. A. Brookes, and R. Stevens, Eds., p. 101, Woodhead Publishing Limited, UK, 2004.

[30] M. Riu-Aumatell, P. Miró, A. Serra-Cayuela, S. Buxaderas, and E. López-Tamames, "Assessment of the aroma profiles of low-alcohol beers using HS-SPME-GC-MS," Food Research International, vol. 57, pp. 196-202, 2014.

[31] D. A. Gee and W. F. Ramirez, "A flavour model for beer fermentation," Journal of the Institute of Brewing, vol. 100, no. 5, pp. 321329, 1994.

[32] J. J. Baert, J. De Clippeleer, P. S. Hughes, L. De Cooman, and G. Aerts, "On the origin of free and bound staling aldehydes in beer," Journal of Agricultural and Food Chemistry, vol. 60, no. 46, pp. 11449-11472, 2012.

[33] C. A. Blanco, C. Andrés-Iglesias, and O. Montero, "Lowalcohol Beers: Flavor Compounds, Defects, and Improvement Strategies," Critical Reviews in Food Science and Nutrition, vol. 56, no. 8, pp. 1379-1388, 2016.

[34] J. De Clippeleer, F. Van Opstaele, J. Vercammen, G. J. Francis, L. De Cooman, and G. Aerts, "Real-time profiling of volatile malt aldehydes using selected ion flow tube mass spectrometry," LCGC North America, vol. 28, pp. 386-395, 2010.

[35] A. Buettner, Springer Handbook of Odor, Springer International Publishing, Cham, Switzerland, 2017.

[36] N. Hashimoto and T. Eshima, "Oxidative degradation of isohumulones in relation to flavour stability of beer," Journal of the Institute of Brewing, vol. 85, no. 3, pp. 136-140, 1979.

[37] M. C. Meilgaard, "Flavor chemistry of beer: part II: flavor and threshold of 239 aroma volatiles," Techical Quarterly MasterBrewers Association of the Americas, vol. 12, pp. 151-168, 1975. 


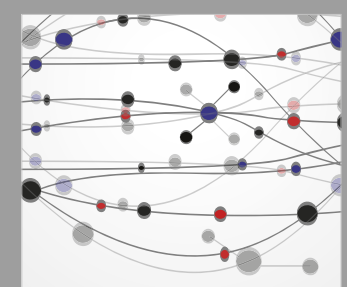

The Scientific World Journal
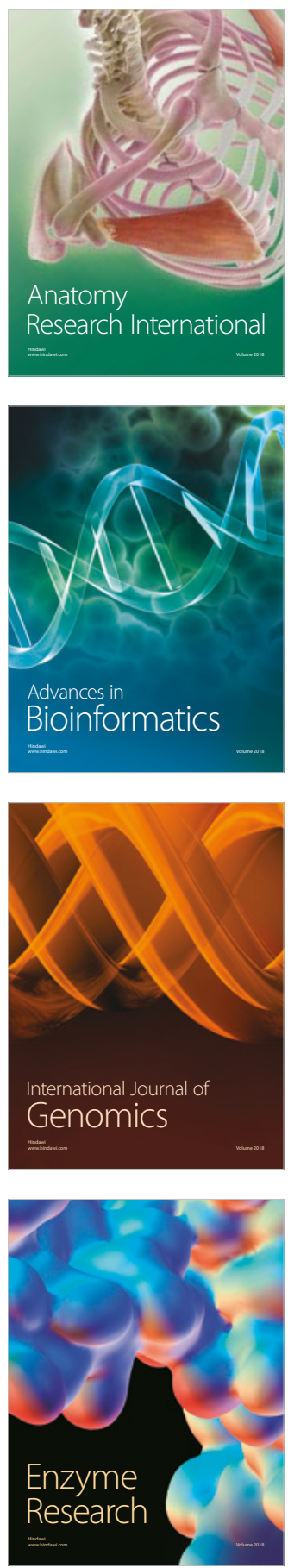
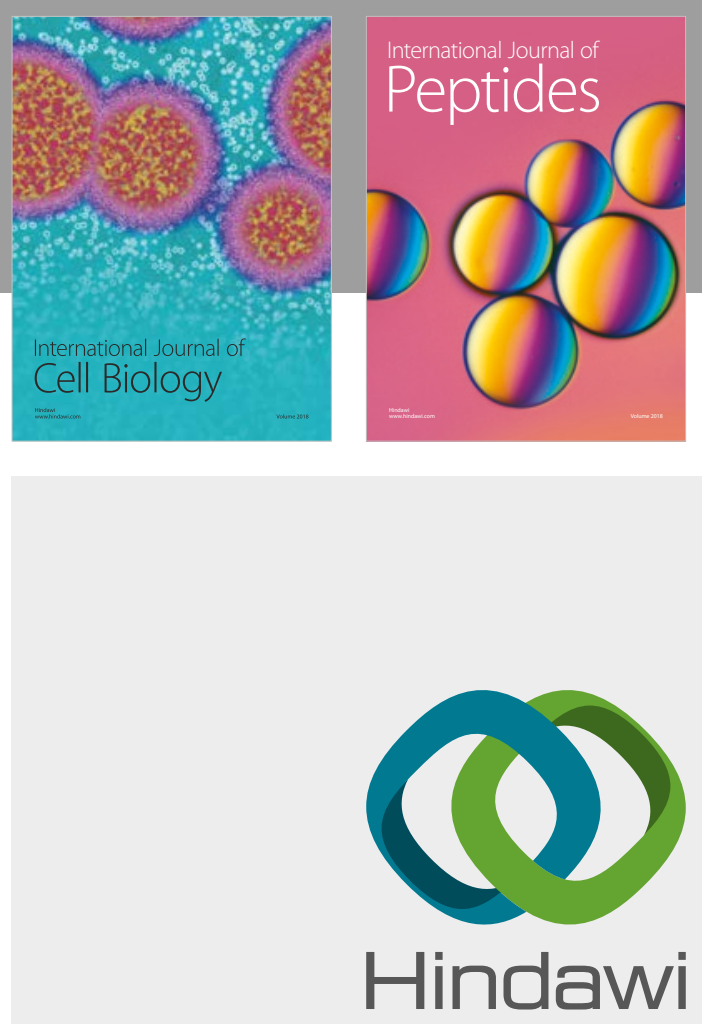

Submit your manuscripts at

www.hindawi.com
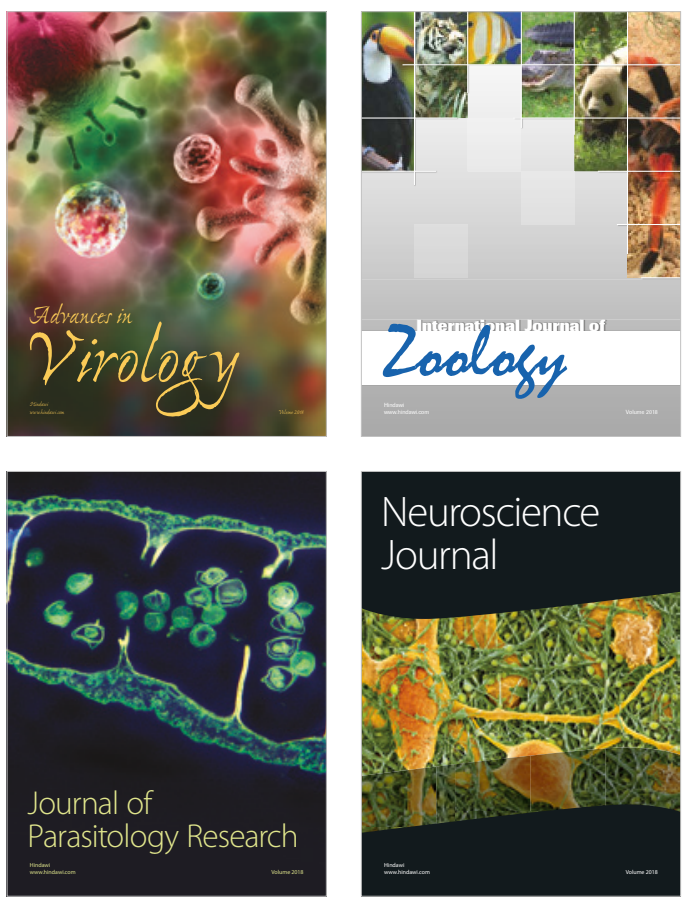
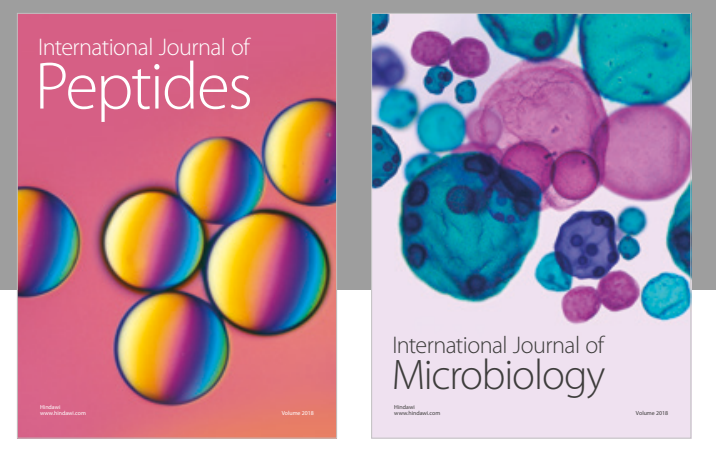

nternational Journal of Microbiology
Journal of
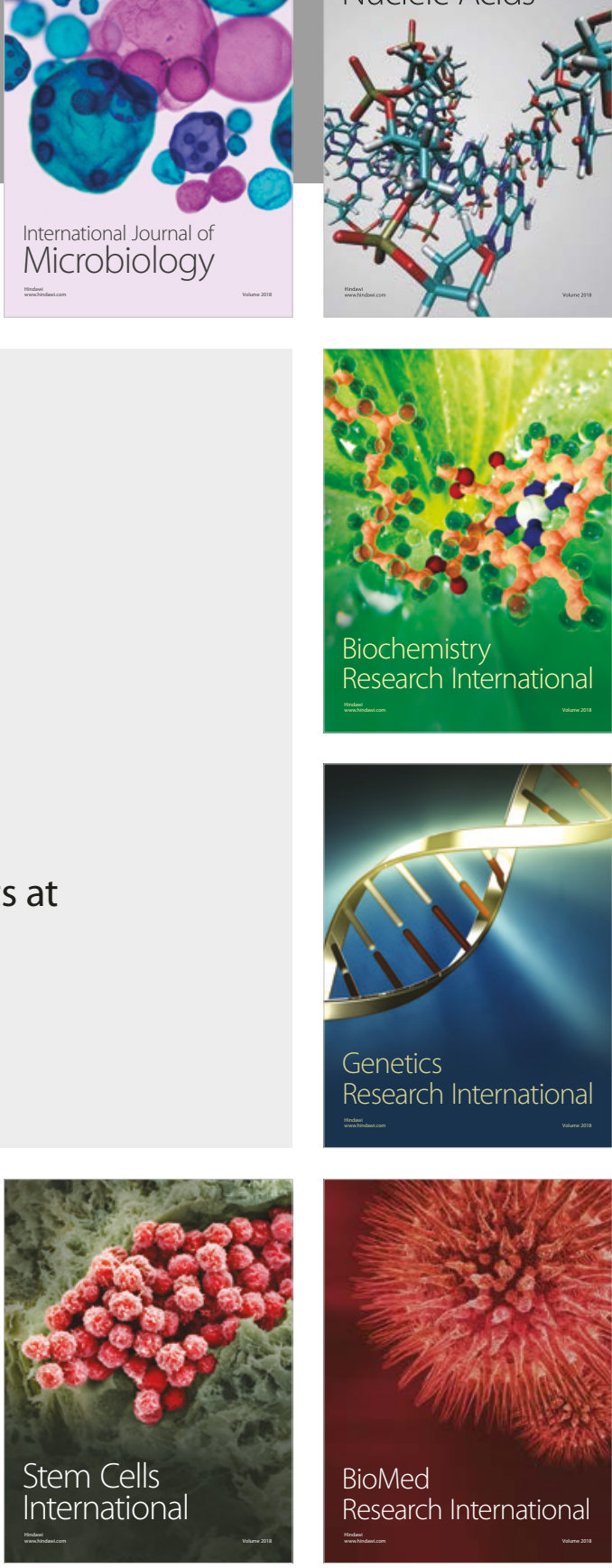
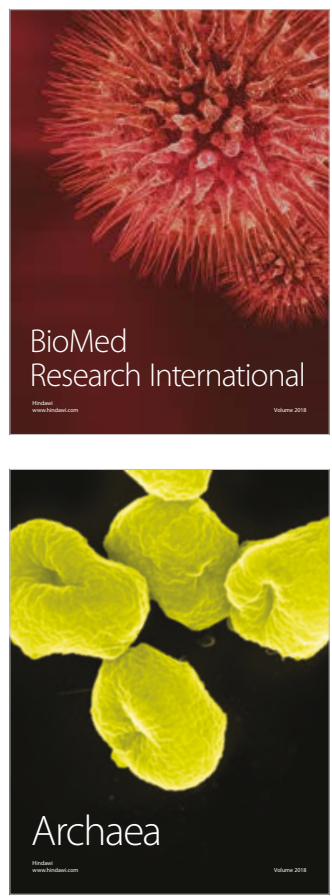